\title{
IMPLICAÇÕES SOCIOAMBIENTAIS DO DESENVOLVIMENTO ECONÔMICO
}

\section{SOCIO-ENVIRONMENTAL IMPLICATIONS OF ECONOMIC DEVELOPMENT}

\author{
Me. Krishna Schneider Treml1 ${ }^{*}$, Dr. Jairo Marchesan², Dr. Sandro Luiz Bazzanela ${ }^{3}$ \\ ${ }^{1}$ Graduada em Direito pela Universidade do Vale do Itajaí (UNIVALI). Mestre em Desenvolvimento Regional pela Universidade do \\ Contestado (UnC), Canoinhas, SC, Brasil.E-mail: krishna_schneider@hotmail.com \\ ${ }^{2}$ Doutor em Geografia pela UFSC. Programa de Mestrado em Desenvolvimento Regional, Universidade do Contestado (UnC), \\ Canoinhas, SC, Brasil.E-mail: jairo@unc.br \\ ${ }^{3}$ Doutor Interdisciplinar em Ciências Humanas pela UFSC. Programa de Mestrado em Desenvolvimento Regional Universidade do \\ Contestado (UnC), Canoinhas, SC, Brasil.E-mail: sandro@unc.br
}

\section{Resumo}

Este artigo tem como objetivo investigar as relações que permeiam a vida humana e as práticas ambientais, as quais, desde a era moderna, estão constante e diretamente associadas aos discursos e práticas jurídicas e econômicas. Nas sociedades contemporâneas, o capital, os bens patrimoniais e o lucro assumem a condição de protagonista de um pressuposto de vida a ser alcançado a qualquer custo pelos indivíduos. Os Estados, sob tais condições, encontram-se cada vez mais pressionados e coagidos pela dinâmica da economia "financeirizada" e reduzidos à condição de agências garantidoras de contratos de remuneração com o capital financeiro global. Demonstram ausência de compromisso com políticas públicas qualitativas inerentes à saúde, à segurança, à educação e ao meio ambiente equilibrado. Nessa direção, em benefício do acesso aos créditos dos investidores os Estados são compelidos a não aplicar ou desregulamentar questões socioambientais, entre outras iniciativas inerentes aos direitos fundamentais da população brasileira. Em consequência, constituem-se novas formas de mal-estar social ligadas à alienação humana, à solidão, à insegurança, à quebra das relações familiares e comunitárias, às desestruturações profissionais, ao individualismo, ao estresse afetivo, bem como à competição agressiva, gerando, consequentemente, visíveis prejuízos decorrentes do balanço geral do desenvolvimento integral. A presente pesquisa foi desenvolvida com base em metodologia bibliográfica e documental. Está fundamentada em vasta referência teórica presente nas obras dos filósofos Giorgio Agamben e Michel Foucault, bem como em livros e artigos de alguns de seus comentaristas do solo brasileiro.

Palavras-chave: Economia; direito; meio ambiente; sociedade.

\begin{abstract}
This article aims to investigate the relationships that permeate human life and environmental practices, which, since the modern era, have been constantly and directly associated with legal and economic discourses and practices. In contemporary societies, the capital, assets and profit assume the protagonist role of a life assumption to be reached at any cost by individuals. States, under such conditions, are increasingly pressured and coerced by the dynamics of the "financialized" economy and reduced to the condition of agencies guaranteeing remuneration contracts with global financial capital. They demonstrate a lack of commitment to qualitative public policies inherent to health, safety, education and a balanced environment. In this sense, for the benefit of access to investor credits, States are compelled not to apply or deregulate socio-environmental issues, among other initiatives inherent to the fundamental rights of the Brazilian population. As a consequence, new forms of social malaise are linked to human alienation, loneliness, insecurity, the breakdown of family and community relationships, professional breakdowns, individualism, affective stress, as well as aggressive competition, generating consequently, visible losses resulting from the overall balance of integral development. This research was developed based on bibliographic and documentary methodology. It is based on a vast theoretical reference present in the works of the philosophers Giorgio Agamben and Michel Foucault, as well as in books and articles by some of his commentators on Brazilian soil.
\end{abstract}

Keywords: Economics; right; environment; society. 


\section{INTRODUÇÃO}

Convivendo na região do Contestado, mais especificamente no Planalto Norte Catarinense, ouve-se, recorrentemente, na sensibilidade comum das pessoas e dos políticos, acerca da necessidade de implementação de empresas que propiciem o almejado desenvolvimento econômico ${ }^{1}$ à população nesse território. Tal publicidade continua periodicamente presente nas campanhas eleitorais, haja vista a existência de suposta correlação entre o empreendedorismo econômico e empresarial, a geração de empregos e o desenvolvimento regional².

Paralelamente, em matéria ambiental, argumenta-se com frequência sobre as possibilidades de manutenção da vida, ou seja, sobre a conservação das condições biológicas de modo a possibilitar a reprodução da vida das mais variadas espécies, com qualidade, às futuras gerações. $O$ intuito é disseminar, nesse contexto, o conceito de desenvolvimento sustentável ${ }^{3}$.

Baseando-se nas premissas que permeiam a relação tríade entre direito, economia e meio ambiente, perquire-se não o ingênuo discurso automatizado e irrefletido acerca da manutenção dos bens ambientais às gerações vindouras. Pelo contrário, por meio deste estudo, busca-se problematizar a vida vivenciada neste tempo, neste habitat, ou seja, questionar a existência humana com fulcro da produtividade e do consumo, desprovida de sentido coletivo, contemplativo, socioambiental, da plena realização humana e do convívio harmônico entre si e com a natureza.

Oportuno esclarecer que não serão abordadas, neste artigo, formas de organização financeira ou termos próprios da ciência econômica, uma vez que o escopo é procurar compreender a relação entre a economia-política, meio ambiente e a vida humana. Em outras palavras, esta produção não busca atender a utilidade das coisas, órgãos, institutos, interesses privados, instituições ou pessoas. Também não objetiva mensurar, por meio de proporções ou estatísticas aritméticas, os passivos ou saldos ambientais remanescentes, mas instigar o intelecto a apreender os fatores que geram a atual condição socioambiental vivenciada pela maior parte da população humana, bem como os impactos decorrentes do processo da plena produção e consumo.

Os esforços e estudos se concentraram numa pesquisa de ordem bibliográfica documental, amparada numa perspectiva multidisciplinar articulada a partir de pressupostos epistemológicos interdisciplinares, em que o direito estabeleceu intercurso dialógico e investigativo com a filosofia, economia, geografia e teologia, áreas de formação e de atuação dos autores deste artigo.

\footnotetext{
${ }^{1}$ Aumento do nível do rendimento nacional auferido por intermédio do produto per capita, com melhoria dos níveis econômicos de vida das pessoas, de modo que possam consumir mais.

${ }^{2}$ Concebe-se desenvolvimento regional como o bem-estar econômico, social, cultural da sociedade humana, bem como, o estabelecimento de relações harmoniosas, de respeito, cuidado e uso parcimonioso dos bens naturais.

${ }^{3} \mathrm{Em} 1983$ foi criada a Comissão Mundial sobre Meio Ambiente e Desenvolvimento, quando o Secretário-Geral da ONU (Organização das Nações Unidas) convidou a médica Gro Harlem Brundtland, mestre em saúde pública e ex-PrimeiraMinistra da Noruega, para presidir a Comissão Mundial sobre Meio Ambiente. Em abril de 1987 a Comissão Brundtland, como ficou conhecida, publicou um relatório inovador intitulado "Nosso Futuro Comum", que traz o conceito de desenvolvimento sustentável para o discurso público, nos seguintes termos: o desenvolvimento sustentável é o desenvolvimento que encontra as necessidades atuais sem comprometer a habilidade das futuras gerações de atender suas próprias necessidades.
} 


\section{ECONOMIA, DIREITO E MEIO AMBIENTE}

A pré-modernidade foi caracterizada pela convivência da sociedade entre grupos formados por relações de parentesco, crença, comunidade religiosa, vizinhança ou ministério, objetivando a promoção de uma organização com o intuito de alcançar o bem-estar comum por intermédio de ações que envolviam a coletividade (BAZZANELLA, 2013).

Prevaleceu, nesse período, o auxílio mútuo entre os membros do grupo ao qual pertenciam e o aconselhamento recíproco para a manutenção da cultura, do desenvolvimento da lavoura, da realização das tarefas domésticas e outros trabalhos, uma vez que havia pouco espaço naquele contexto para o indivíduo e para as manifestações subjetivas (BAZZANELLA, 2013).

Sob tais pressupostos, é preciso considerar que até os séculos XVI e XVII a rotina das pessoas que compunham uma família, uma comunidade, não estava organizada em torno do trabalho - tarefa árdua e humilhante aos gregos ainda na Grécia Antiga -, mas por necessidade de subsistência. As pessoas dispensavam algumas horas do dia em prol de uma atividade laborativa que proporcionasse o seu sustento e o de seus dependentes.

Basicamente, a rotina de um tecelão, por exemplo, estava inscrita em aproximadamente 3 (três) horas e 30 (trinta) minutos de trabalho diário, cujo período era interrompido por intervalos de descanso, conversa com familiares, amigos - sempre ausente a necessidade de ampliar a produção e, consequentemente, aumentar a receita oriunda da produtividade -, o que caracterizava uma prática tradicionalista (BAZZANELLA, 2013).

Contudo, com o advento da Reforma Protestante - movimento religioso promovido e protagonizado por Martin Lutero (1483-1546), no Século XVI - disseminou-se o conceito e as prerrogativas da palavra "vocação". De origem bíblica, "vocação" trouxe como sentido primordial a ideia de que o Filho de Deus conferiu a cada indivíduo uma tarefa que deveria ser desempenhada como forma de demonstrar o amor a Deus e ao próximo. É o culto diário a Ele. "Tementes a Deus, os homens devem exercê-la da melhor forma. Na medida em que a cumprem, os homens são recompensados com dádivas, desde a riqueza na terra até a riqueza nos céus" (BAZZANELLA, 2013, p. 43).

Com fundamento em tais práticas, o historiador, sociólogo, economista e político Maximillian Karl Emil Weber (1864 a 1920), identificou, por intermédio das interpretações sobre as relações existentes entre os atos religiosos e as organizações econômicas, um importante fenômeno acerca da necessidade do trabalho na vida das pessoas. Weber pesquisou a sociologia da religião, mais especificamente da religião protestante, e publicou seus estudos na obra intitulada "Ética Protestante e o Espírito do Capitalismo", em 1905.

A referida obra contém perspectivas analíticas acerca da compreensão dos fatos históricos e sociais que se constituíram em fundamento das práticas modernas adotadas no ocidente, sobretudo com o advento do mercantilismo, e, posteriormente do capitalismo, as quais vinculam diretamente a atividade laborativa econômica à doutrina e práticas religiosas.

Nas análises feitas por Weber sobre as doutrinas da fé, os protestantes trabalham constante e periodicamente como um culto diário - para obter a salvação de suas almas e, consequentemente, assegurar um lugar ao céu, ao invés de simplesmente gozar uma vida ausente de uma utilidade ou finalidade.

O racionalismo religioso e econômico, estudado por Weber, permitiu comparações entre as atividades econômicas realizadas no Ocidente e no Oriente, cujas descobertas vincularam 
estreitamente o capitalismo ao protestantismo nas práticas intrínsecas econômico-religiosas adotadas e praticadas pelas sociedades ocidentais.

$\mathrm{Na}$ ordem societária contemporânea é possível constatar que tais premissas também são facilmente evidenciadas na ortodoxia católica, a qual é representada pela figura do salvador numa unidade da trindade (Pai, Filho e Espírito Santo), que, dentro das premissas econômicas e dos mistérios da Santa Fé, conduz a sociedade humana à vida eterna, como argumenta Agamben:

Por isso não causa surpresa que um economismo radical, que, distinguindo no Filho duas vontades, ameaça a própria unidade do sujeito cristológico, tenha necessidade de afirmar a unidade entre teologia e economia, enquanto um teologismo, que procura salvaguardar a qualquer preço a unidade, não hesita em opor com vigor os dois discursos. A distinção entre as duas racionalidades atravessa continuamente o plano das disputas teleológicas e, assim como a dogmática trinitária e a cristologia se formaram juntas e não podem de modo algum ser divididas (AGAMBEN, 2011, p. 78).

Tais ações ostentam a finalidade substancial no governo da vida e do meio ambiente de uma maneira biopolítica ${ }^{4}$, com a necessidade do poder de receber a aclamação da glória. Nesse sentido, o governo é aquela habilidade de exercício do poder na configuração de uma economia. Tanto o pastorado eclesial como o governo político estatal estão localizados no interior do paradigma substancialmente econômico (AGAMBEN, 2011).

Sob esse enfoque, num movimento indagativo a respeito da glória e da glorificação - numa aproximação entre reino e governo, teologia e economia -, o filósofo italiano Giorgio Agamben publicou a obra: "O Reino e a Glória: uma genealogia teleológica da economia e do governo: homo sacer II". Para o autor, se o reino e o governo estão dissociados de Deus, logo, nenhum governo do mundo se torna efetivo, resultando num poder soberano impotente e em violentas providências particulares. "O governo é, portanto, um epifenômeno das providências (ou do reino)" (AGAMBEN, 2011, p.134).

Nesta realidade político-econômica, evidencia-se plenamente a entrada do Estado mercantilista no lugar que antes era ocupado por Deus soberanamente. Era Deus quem determinava as prerrogativas vitais aos seres humanos que estavam em busca do reino dos céus. Em substituição a Ele, o Estado é o pastor que governa as ovelhas, a humanidade rumo à vida eterna. "Ser governo político nada mais é do que a arte de exercer o poder na forma de uma economia, pastorado eclesiástico e governo político situam-se, ambos no interior de um paradigma essencialmente econômico" (AGAMBEN, 2011, p. 126).

Assim, numa síntese econômica teleológica, a continuidade do exercício do poder soberano exercido por Deus, que reinou supremamente com seus anjos por intermédio de princípios em face aos seus súditos (AGAMBEN, 2011), do pastor às suas ovelhas, do padre aos cristãos, do Pai de família aos seus filhos, está o Estado que, contemporaneamente, exerce o poder e governa na forma de uma economia-política teleológica, reduzindo as ovelhas à mera condição de produtores e consumidores.

Com base em tais premissas, a casa-mundo é governada por um princípio único. “O poder todo poder, tanto o humano quanto o divino - devem manter juntos esses dois polos, ou seja, ao mesmo tempo, reino e governo, norma transcendente e ordem imanente" (AGAMBEN, 2011, p. 97). De tal forma, as coisas e os acontecimentos mundanos estão ordenados enquanto mantêm relação terrestre com o fim divino. Ou seja, as atividades humanas devem ser desenvolvidas com

\footnotetext{
${ }^{4}$ A biopolítica se caracteriza pela dominação do próprio corpo por um controle externo, ou seja, é a inclusão da vida biológica dos sujeitos sob o controle e manipulação da esfera política (AGAMBEN, 2010).
} 
fundamento nos preceitos do governo de Deus, numa vinculação político-religiosa, como complementa Agamben:

A fácil explicação instrumental, segundo a qual se trataria de um estratagema dos poderosos para justificar sua ambição ou de uma encenação a fim de provocar temor reverencial e obediência nos súditos, por mais que possa ocorrer, não é capaz de explicar uma conexão tão profunda e original, que envolve não só a esfera política, mas também religiosa (AGAMBEN, 2011, p. 215).

$\mathrm{Na}$ consecução das atividades divinas hierárquicas, o poder soberano governa com o apoio dos executores, assistentes de Deus - os anjos - que administram a casa celestial. "Os anjos são os fiadores da relação originária entre a Igreja e a esfera política, do caráter púbico e políticoreligioso do culto que celebra tanto na ekklesia quanto na cidade celeste" (AGAMBEN, 2011, p. 164).

Num paralelismo estruturado entre o governo celestial e o governo dos homens, é possível constatar que se refletem as imagens do poder por excelência. Enquanto o governo celestial é administrado com o apoio dos anjos, o governo terreno o faz com a assistência dos ministros, apóstolos, chanceleres, principados e potestades. Essa estrutura operacional se traduz numa máquina governamental, sendo que "em ambos os tratados a hierarquia é em si mesma o princípio que efetua a salvação e a deificação" (AGAMBEN 2011, p. 171), e tem sua origem na economia trinitária, da qual derivam todas as coisas.

Não obstante, nesta relação de equivalência entre burocracia celestial e burocracia terrena torna-se possível, na Terra, a repetição do modelo da administração celeste como a estrutura necessária para a realização de um oficio, de um ministério que leve todos à salvação no dia do juízo final, formada santamente por ordens transmitidas por Deus, as quais se limitam tanto quanto é possível pelos homens (AGAMBEN, 2011). Em outras palavras, o exercício Dele sobrevive na Glória. "A glória, é então, aquilo que deve cobrir com seu esplendor a figura indescritível da inoperosidade divina" (AGAMBEN, 2011, p. 180), refletindo-se numa administração terrena realizada por intermédio do governo e inúmeros incontáveis ministérios como resultado de uma teologia política:

Se hoje assistimos ao domínio arrasador do governo e da economia sobre uma soberania popular esvaziada de qualquer sentido, isso significa talvez que as democracias ocidentais estejam pagando as consequências políticas de uma herança teleológica que, por intermédio de Rousseau, assumiram sem se dar conta (AGAMBEN, 2011, p. 299).

O significado técnico-jurídico do tema exposto traduz-se numa esfera constitutiva da soberania, marcada por cerimônias, insígnias ou sinais de domínio, de poder, e caracteriza um monopólio de prerrogativas, inclusive jurídicas, originadas à pompa do poder soberano. $\mathrm{O}$ que parecia apenas uma questão de símbolos, formalidades e vestuário, produz mudanças decisivas para o ser humano e para a sua relação com o direito. "É uma fé cega que necessita da lei (da vontade geral) como instrumento do governo no mundo" (AGAMBEN, 2011, p. 294).

Sob tais perspectivas, a oikonomia ${ }^{5}$ foi substituída pela economia, que passou a se constituir como governo da vida, substituindo Deus pelos preceitos econômicos aplicados à casa-

\footnotetext{
5“Para Aristóteles, oikonomia relaciona-se à administração da casa, das relações vitais que se estabelecem no âmbito privado da oikos. Desta forma, fica patente nos pressupostos do filósofo estagirita, o fato de que as atividades próprias da oikonomia diferem substancialmente da atividade política desenvolvida em praça pública pelos cidadãos no uso da liberdade" (BAZANELLA, 2015, p. 45). Assim, na acepção grega, a vida natural ou biológica é mantida e reproduzida no espaço da Oikos, casa, em razão da necessidade de condições básicas e indispensáveis à sobrevivência e manutenção da vida biológica. Oikonomia, portanto, é um conceito que está intrinsecamente relacionado à lei ou à
} 
mundo, a um território, a um país. "Uma cidade é, por natureza, algo múltiplo, e se torna demasiado uma, será antes uma casa [oikia] que uma cidade" (AGAMBEN, 2011, p. 35).

Verifica-se, portanto, que "com o termo oikonomia acontece algo parecido com o que ocorre com o termo empresa, que, com o consentimento mais ou menos consciente dos interessados, foi se estendendo até cobrir âmbitos que nada tinham a ver com ele, como por exemplo, a universidade" (AGAMBEN, 2011, p. 35).

Ou seja, a administração com fins econômicos atinge hoje não somente as empresas, estatais, multinacionais, transnacionais, mas é encontrada em todos os espaços e tempos vitais, como nas casas, nas escolas, nos hospitais, museus, unidades de conservação, parques ecológicos, patrimônios legalmente protegidos e também no Estado. É unânime a utilidade que as instituições, sejam elas públicas, privadas ou de economia mista, assumem. Trata-se de uma serventia validada constantemente pelo poder soberano e por instituições, técnicos, burocratas, consultores e especialistas que compõem a máquina governamental que mantém essa engrenagem circulando, como esclarece Agamben:

O que nossa investigação mostrou é que o verdadeiro problema, o arcano central da política, não é a soberania, mas o governo, não é Deus, mas o anjo, não é o rei, mas o ministro, não é a lei, mas a polícia - ou seja, a máquina governamental que eles formam e mantêm em movimento (AGAMBEN, 2011, p. 299).

Nessa perspectiva, o autor conclui que o principal enigma da política não é o poder soberano, o poder executivo, a figura principal do Estado, mas a máquina governamental que sustenta o Estado por intermédio de um vasto número de técnicos e burocratas que o assistem num complexo jogo de interesses. Tal estrutura governamental, sustentada por meio de relações de poder centralizadas num estado de exceção ${ }^{6}$, interfere, rege e captura a vida humana em sua integralidade, formando uma aliança entre o reino e o governo em face ao pastorado. "São os corpos absolutamente matáveis dos súditos que formam o novo corpo político do Ocidente" (AGAMBEN, 2010, p. 122). São vidas matáveis e ecossistemas destrutíveis.

Com isso, a partir de pressupostos biopolíticos, "no sistema do Estado-nação, os ditos direitos sagrados e inalienáveis do homem mostram-se desprovidos de qualquer tutela e de qualquer realidade no mesmo instante em que não seja possível configurá-los como direitos dos cidadãos de um Estado" (AGAMBEN, 2010, p. 123). Ou seja, num contexto em que os corpos podem ser mutilados, destituídos de sua sacralidade e insacrificabilidade, esquecidos e abandonados, os bens naturais podem, igualmente, ser depredados e aniquilados, sem que tais ações imputem responsabilidade ao poder soberano que opera em permanente estado de exceção.

Portanto, a economia escapa da lógica de trabalhar e produzir para viver e se submete à esfera dos Estados e do interesse do crescente capital.

\footnotetext{
administração da família e da casa, respondendo às necessidades cotidianas de sobrevivência e a manutenção da vida dos seus membros.

6“Exceção é uma espécie de exclusão. Ela é um caso singular, que é excluído da norma geral. Mas, o que caracteriza propriamente a exceção é que aquilo que é excluído não está, por conta disto, absolutamente fora de relação com a norma; ao contrário, essa se mantém em relação com aquela na forma da suspensão. A norma se aplica à exceção desaplicando-se, retirando-se desta. O estão de exceção não é, portanto, o caos que precede a ordem, mas a situação que resulta da sua suspensão" (AGAMBEN, 2004, p. 24). "O estado de exceção é, neste sentido, a abertura de um espaço em que a aplicação e norma mostram sua separação e em que uma pura força de lei realiza (isto é, aplica, desaplicando) uma norma cuja aplicação foi suspensa" (AGAMBEN, 2004, p. 63).
} 


\section{A TRÍADE RELAÇÃO ENTRE ECONOMIA, DIREITO E MEIO AMBIENTE}

\subsection{Aspectos econômicos}

Com base nas prerrogativas de financeirização e nas premissas teológicas acima descritas, altera-se consubstancialmente o conceito da palavra trabalho, que deixa de ser uma atividade para suprir as necessidades básicas de sustentação do ser humano, e passa a ser compreendida como uma prática divina e moral vinculada à esfera econômica que promove a salvação do indivíduo. "Se antes o acúmulo patrimonial e monetário era visto como pecaminoso sinal de apego às coisas materiais e terrenas, ele agora passa a ter uma conotação positiva" (BAZZANELLA, 2013, p. 43).

Nessa perspectiva, o dinheiro passa a ser o último fim almejado pelos seres humanos, decorrente da prática de uma vocação divina que traz consequências benignas, como o acúmulo de bens e capital, os quais se transformam imediatamente numa ação vital moralmente aceita e bem-vista pela sociedade. Sob os imperativos de salvação pela via do acúmulo do capital e do acesso ao consumo, o ócio, o tempo livre, ou até a perda de tempo (mesmo que isso signifique o cuidado do ser humano, encontrar-se consigo mesmo e com os outros) apresentam-se como situações pecaminosas e inafiançáveis.

Com fundamento nestas diretrizes modernas, as sociedades contemporâneas elegem alguns pré-requisitos econômicos baseados no trabalho, na produtividade e no consumo como fatores preponderantes que orientam a vida em sociedade, transformando-os em premissas indispensáveis para uma vida plena, feliz e que conduza à salvação pela via do acúmulo de capital e de bens de consumo. $O$ trabalho não é mais para abastecer e manter a família com as condições de sobrevivência, mas o fazer pelo qual se glorifica a Deus, invocando a primazia do homo faber $^{7}$ (AGAMBEN, 2011).

Ademais, é possível enfatizar que a ciência econômica se destacou como disciplina científica recentemente. A comunidade literária costuma datar seu início a partir da publicação da obra: "A Riqueza das Nações", de Adam Smith, em 1776, livro que marcou uma mudança na natureza da reflexão sobre os temas econômicos. Obviamente, muitos autores já faziam ponderações sobre o tema, ou sobre determinados tópicos econômicos ou relacionados à economia. Nesse sentido, complementa a politóloga Hannah Arednt:

A economia - que até a era moderna constituía uma parte não muito importante da ética e da política, e que se baseia na premissa de que os homens agem em relação às suas atividades econômicas como agem em relação a tudo mais - só veio adquirir caráter

\footnotetext{
7 Para Hannah Arendt, na obra "A Condição Humana", o declínio do espaço público, da ação, da política e do exercício da cidadania, enquanto, manifestações da liberdade política consolidaram-se na modernidade com a ascensão do homo faber. É o homem vinculado visceralmente ao trabalho e à fabricação de objetos (outrora realizado no âmbito da casa como exigência do reino da necessidade, das estratégias de sobrevivência biológica) e que ascende ao espaço público e o torna, por excelência, o espaço da produção e da circulação de bens materiais implicados na dinâmica econômica moderna. A economia moderna, em sua dimensão de transcendência, impõe ao homo faber a dedicação ao trabalho como condição do conhecimento de si, como condição do seu reconhecimento social. O ser humano se define pelo que fabrica, produz. BAZZANELLA, Sandro Luiz. A CENTRALIDADE DA VIDA EM NIETZSCHE E AGAMBEN FRENTE À METAFíSICA OCIDENTAL E A BIOPOLÍTICA CONTEMPORANEA. Florianópolis: UFSC, 2010, P. 94. Tese de doutorado disponível

em: https://repositorio.ufsc.br/handle/123456789/94701\#: :text=em\%20Ci\%C3\%AAncias\%20Humanas-

,A\%20Centralidade\%20da\%20vida\%20em\%20Nietzsche\%20e\%20Agamben\%20frente,ocidental\%20e\%20a\%20biopol\% C3\%ADtica\%20contempor\%C3\%A2nea\&text=Nietzsche\%20ao\%20conceber\%20a\%20vida,mediocrizante\%20presente \%20em\%20seu\%20tempo. Acessado em 01/08/2020.
} 
científico quando os homens se tornaram seres sociais e passaram a seguir unanimemente certos padrões de comportamento, de sorte que aqueles que não seguissem as regras podiam ser considerados associais ou anormais (ARENDT, 2014, p. 51).

Assim, compreende-se que até a era moderna inexistiam indícios de discursos que tratassem da ciência econômica fora da oikonomia ${ }^{8}$ como um sistema, uma unidade reguladora das sociedades. Na época, os atos econômicos estavam impingidos nas relações sociais.

Paradoxalmente, na modernidade se dá a ruptura da continuidade da oikonomia, mediante a instituição de um discurso com pretensões de definir os pressupostos de uma ciência econômica, a qual se reveste de características sacras, que culminam no estabelecimento dos imperativos da lei de mercado, conforme argumenta Bazzanella:

Apresenta-se, neste contexto, uma das características constitutivas da máquina governamental e oikonomica ocidental, na medida em que a economia se apresenta como transcendência que, através de um articulado sistema de crenças, de leis de mercado revestidas da aura da sacralidade, dirige e determina, através de mão invisível, os destinos humanos. Compete ao governo, no plano da imanência, operacionalizar as verdades reveladas pela economia na administrabilidade da vida e da morte dos seres humanos, e da vida em sua totalidade (BAZZANELLA, 2015, p. 51).

Sob tais diretrizes é preciso reconhecer que as concepções e relações de vida na modernidade e, sobretudo, na contemporaneidade, são conduzidas pela lógica da crescente produção aliada ao pleno consumo. Desse modo, a era moderna reflete o persistente tratamento de todos os objetos, especialmente os bens naturais como recursos a disposição dos seres humanos, como bens consumíveis.

Nessas condições, a era moderna é mais adequadamente representada, para Hannah Arendt, pela promoção e incentivo ao trabalho que promove a produtividade e o consumo, conforme segue:

Ao definir o trabalho como "o metabolismo do homem com a natureza", em cujo processo o material da natureza é adaptado, por uma mudança de forma, às necessidades do homem, de sorte que, o trabalho se incorpora ao seu sujeito [...] não podendo mais o indivíduo despir-se dele sem que perca sua dignidade, sua credencial para manutenção dos requisitos indispensáveis ao convívio social. O motivo da promoção do trabalho na era moderna foi a sua "produtividade" (ARENDT, 2014, pp. 122/106).

Em tal dinâmica produtiva, o sistema de controle do oikos, do tempo, da vida, dos ecossistemas e até dos corpos dos indivíduos, se manifesta por meio de estratégias de obediência e regulação que interferem nas relações sociais e ambientais, nas quais o discurso econômico penetra e guia a vida dos indivíduos e da população. A cada dia a população é controlada por uma série de artifícios de marketing, publicitários, produtivos, econômicos e de consumo, com o objetivo de gerir e conduzir a vida dos sujeitos. Com isso, a influência cada vez maior e mais profunda do Estado nas relações socioambientais - com o intuito de aumentar e aperfeiçoar suas garantias - fica evidente.

\footnotetext{
${ }^{8}$ Nesse contexto, oikonomia pode ser compreendida não só como a organização e administração do contexto familiar pela autoridade patriarcal, mas o chefe do núcleo doméstico faz também a gestão dos filhos, das mulheres, dos bens da casa e do trabalho agrícola. Para Agamben (2011), "oikonomia significa a organização da casa. Contudo, importa não esquecer que oikos não é a casa unifamiliar moderna, nem simplesmente a família ampliada, mas um organismo complexo no qual se entrelaçam relações heterogêneas. Aqui, segundo uma reflexão semântica, que ficará inseparável do termo, designa uma prática e um saber não epistêmico que, em si mesmos, até podem parecer não conformes ao bem e só podem ser julgados no contexto das finalidades que perseguem" (AGAMBEN, 2011, p. 31-33).
} 
Esse modelo de vida e de mundo, cujas apostas foram lançadas na modernidade, supõe levar os seres humanos ao alcance do progresso (econômico), sem considerar as ambivalências ${ }^{9} \mathrm{e}$ os efeitos colaterais da destruição do meio ambiente e da captura da vida plena pela biopolítica.

Sobre a temática, Hannah Arendt discorre que o Estado, na contemporaneidade, libertou os homens para o desenvolvimento de forças produtivas sociais, para a produção comum de mercadorias necessárias à vida feliz (ARENDT, 2014). Mesmo que essa suposta vida feliz reduza os cidadãos à condição de produtores e consumidores de mercadorias, de si mesmos, dos ecossistemas, de relações com outros e, sobretudo, com a casa-mundo.

$\mathrm{Na}$ sociedade da plena produção e pleno consumo os indivíduos são rotulados, homogeneizados, padronizados sob premissas do sistema capitalista que aglutina todos os ideais e intuitos de uma vida profana. Tal fenômeno, na linguagem filosófica-política atual, pode ser conceituado como alienação ${ }^{10}$, caracterizada por um estado do sujeito que não pertence mais a si próprio. Ou seja, de uma forma de ser humano que não detém mais o controle de si ou que se vê privado dos seus direitos humanos fundamentais no momento em que não contempla a sua totalidade autossuficiente. A partir desse movimento, ausente da racionalidade operante e ativa, pode ser equiparado a um "item", uma "coisa". Torna-se um homem esterilizado, banalizado, irracional, que não apenas perde-se de si próprio, mas perde-se em sua própria casa-mundo.

\subsection{Aspectos jurídicos}

A estreita relação entre teologia e política, num ordenamento jurídico suspenso pelo poder soberano em permanente estado de exceção, tende a confundir-se com a própria vida normal, inaugurando um paradigma político-jurídico, pelo qual tudo é possível. Ou seja, constata-se que "a exceção é uma espécie de exclusão" (AGAMBEN, 2010, p. 24), em cujo contexto os seres humanos - dotados de linguagem e racionalidade - convivem com um sistema jurídico vigente, mas inexecutável, inexequível e inválido em que as leis, normas e métodos são desconsiderados e inaplicáveis. "O Direito tem caráter normativo, é norma (no sentido próprio de esquadro) não porque comanda e prescreve, mas, enquanto deve, antes de mais nada, criar o âmbito da própria referência da vida real, normatizá-la" (AGAMBEN, 2010, p. 32), o que definitivamente não ocorre na contemporaneidade. Atualmente, o ordenamento jurídico é demandado em sua mera instrumentalidade, em circunstâncias determinadas, apenas como forma de sanção, de

\footnotetext{
9“Estado caracterizado pela presença simultânea de valorizações ou de atitudes contrastantes ou opostas. Esse termo é usado especialmente em psicologia para indicar certas situações emotivas que implicam amor e ódio, e em geral atitudes opostas em face do mesmo objeto" (ABBAGNANO, 2007, p. 36-37). Para Zygmunt Bauman, a ambivalência se caracteriza pela "possibilidade de conferir a um objeto ou evento mais de uma categoria, é uma desordem específica da linguagem, uma falha da função nomeadora (segregadora) que a linguagem deve desempenhar. 0 principal sintoma da desordem é o agudo desconforto que sentimos quando somos incapazes de ler adequadamente a situação e optar entre ações alternativas. É por causa da ansiedade que a acompanha e da consequente indecisão que experimentamos a ambivalência como desordem ou culpamos a língua pela falta de precisão ou a nós mesmos por seu emprego incorreto" (BAUMAN, 1999, p. 09).

${ }^{10}$ No sentido que lhe é dado por Marx, ação pela qual (ou estado no qual) um indivíduo, um grupo, uma instituição ou uma sociedade se tornam (ou permanecem) alheios, estranhos, enfim, alienados aos resultados ou produtos de sua própria atividade (e à atividade ela mesma), e/ou à natureza na qual vivem, e/ou a outros seres humanos, e - além de, e através de - também a si mesmos (às suas possibilidades humanas constituídas historicamente). Assim concebida, a alienação é sempre alienação de si próprio ou autoalienação, isto é, alienação do homem (ou de seu próprio ser) em relação a si mesmo (às suas possibilidades humanas), através dele próprio (pela sua própria atividade) (BOTTOMORE, 2001, p. 5). Na perspectiva filosófica marxista, a alienação é entendida como a situação em que o indivíduo se torna alheio de si e da natureza - não mais se pertence ou se reconhece. Consequentemente, não possui mais autonomia, pois está privado dos seus direitos - coisificado (MARCHESAN, 2007).
} 
penalização ao delito praticado pelo sujeito e não como agente regulador da vida humana em sociedade.

Como enfatiza Agamben (2010), “a ordem jurídica não se apresenta em sua origem simplesmente como uma sansão de um fato transgressivo, mas, constitui-se sobretudo, através do repetir-se do mesmo ato sem sansão alguma" (p. 33). Num contexto comparativo, é como permitir o crime continuado de destruição de mata nativa, ausente de qualquer punição aos autores pelo poder soberano. O filósofo correlaciona ainda mais um exemplo que ilustra tal abordagem:

\footnotetext{
O que temos hoje diante dos olhos é, de fato, uma vida exposta como tal a uma violência sem precedentes, mais precisamente nas formas mais profanas e banais. O nosso tempo é aquele em que um weekend de feriado produz mais vítimas nas autoestradas do que uma campanha bélica (AGAMBEN, 2010, p. 113).
}

Neste contexto, o que chama atenção é o fato da adequação das ideias do filósofo e jurista Agamben à realidade jurídica, inclusive ambiental, no momento em que a lei é promulgada, está vigente, mas permanece suspensa e sem eficácia no universo jurídico. É evidente a existência de leis que asseguram a pena aos infratores, contudo, a estrutura governamental não possibilita a aplicabilidade de tais normas aos episódios concretamente manifestados. "Chamemos de relação de exceção a esta forma extrema da relação que inclui alguma coisa unicamente através da exclusão" (AGAMBEN, 2010, p. 25).

Em outras palavras, refere-se a uma lei que tem vigência, mas não significa, não vigora, não é executável, o que demonstra que não há garantias jurídicas formais em si mesma. Ou seja, que a efetividade de um ordenamento jurídico está intimamente vinculada à capacidade de mobilização social constante na defesa dos direitos e cumprimento dos deveres públicos. "Uma vigência sem significado objeta que uma lei que perdeu seu conteúdo cessa de existir como tal e se confunde com a vida" (AGAMBEN, 2010, p. 58); se confunde com a regra, com a normalidade.

Tal condição se estabelece e se justifica na medida em que "a validade de uma norma jurídica não coincide com sua aplicação ao caso particular, por exemplo, em um processo ou em um ato executivo; ao contrário, a norma, justamente por ser geral, deve valer, independente do caso particular" (AGAMBEN, 2010, p. 27). Essa premissa exige a distinção precisa em relação aos fatos e aos preceitos legalmente codificados, independente das partes envolvidas e do local do delito. Enfim, a norma deve ser aplicada unanimemente a todos os infratores que cometem atos antijurídicos. "Existe uma figura-limite, um limiar em que ele está, simultaneamente, dentro e fora do ordenamento jurídico, e este limiar é o lugar da soberania” (AGAMBEN, 2010, p. 33).

Destarte, sob as perspectivas apresentadas,

\footnotetext{
a oposição entre zoé e bíos, zên, e eû zên (ou seja, entre a vida em geral e o modo de vida qualificado que é próprio dos homens), ainda que tão decisiva para a origem da política ocidental, não contém nada que possa fazer pensar em um privilégio ou em uma sacralidade da vida como tal (AGAMBEN, 2010, p. 71).
}

Nesse prisma, "não se entende, porém, de modo algum, porque o homo sacer possa ser morto por qualquer um sem que se manche de sacrilégio" (AGAMBEN, 2010, p. 75/76), situando a vida entre uma sacralidade e uma matabilidade. Entre um santo e um maldito. Entre o imaculado e o amaldiçoado. No mundo dos conceitos, como no caso do homo sacer, "há um momento em que eles perdem a sua inteligibilidade imediata e, como todo termo vazio, podem carregar-se de sentidos contraditórios" (AGAMBEN, 2010, p. 82). Esse não se caracteriza pela vida natural 
reprodutiva (zoé), tampouco uma forma de vida qualificada (bios), mas, sobretudo, uma vida nua ${ }^{11}$, uma vida meramente biológica, é uma vida lançada numa zona de indiferença.

Dada essa circunstância, "na figura desta vida-sacra, que algo como a vida nua faz aparição no mundo Ocidental. Decisivo é, porém, que esta vida-sacra tenha desde o início um caráter eminentemente político e exiba uma ligação essencial com o terreno sobre o qual se funda o poder soberano" (AGAMBEN, 2010, p. 100). O direito, a razão jurídica externa que deveria dar limites ao poder soberano, acaba se tornando um mecanismo racionalizado, disponível pelo chefe de Estado em face aos seus comandados, utilizado como meio para atingir os seus objetivos. "Pois bem, esse instrumento intelectual, o tipo de cálculo, a forma de racionalidade que permite que a razão governamental se autolimite não é o Direito" (FOUCAULT, 2008, p. 18).

Pode-se considerar, portanto, que "na sua forma extrema, aliás, o corpo biopolítico do Ocidente se apresenta como um limiar de absoluta indistinção entre direito e fato, norma e vida biológica" (AGAMBEN, 2010, p. 182). É um consentimento inconsciente pelos súditos de que o corpo humano, a vida biológica - na sua condição reprodutiva -, mantém subserviência a um sistema dominado por um poder supremo que impõe regras, violentando, normatizando e manejando vida humana e os ecossistemas.

Nesta perspectiva normatizante constata-se a aceitação de um reducionismo legal aos atos normativos, injunções e, consequentemente, a perda de direito à saúde, à educação, bem como à tutela das questões ambientais e ao bem-estar da sociedade. Isso ocorre em obediência às estruturas econômicas, as quais, mediante experiências, sofisticadas técnicas políticas e avanços tecnológicos apropriados, caracterizam "uma inclusão exclusiva da vida nua no Estado" (AGAMBEN, 2010, p. 106).

Agamben (2010), sobre a análise, a representação e atuação dos cidadãos na política, num estado de exceção caracterizado pelo exercício da violência soberana, na contemporaneidade, esclarece que:

A este estatuto particular do jus puniendi, que se configura como uma sobrevivência do estado de natureza no próprio coração do Estado, corresponde nos súditos à faculdade não de desobedecer, mas de resistir à violência exercitada sobre sua própria pessoa, porque nenhum homem se supõe que seja obrigado por pacto a não resistir à violência, e, por consequência, não se pode supor que ele dê aos outros o direito de pôr violentamente as mãos sobre a sua pessoa (AGAMBEN, 2010, p. 106).

Dessa maneira, ao invés da inacessibilidade e da suspensão dos direitos sociais, num sistema jurídico-econômico-político que se constitui num mercado jurisdicional para justificar a legitimidade dos governantes, o Estado deveria respeitar as leis divinas, morais, naturais, e, sobretudo as leis (fundamentais) do homem, bem como utilizar as normas jurídicas como mecanismo de delimitação da governabilidade.

\footnotetext{
11“É como se toda valorização e toda "politização" da vida (como está implícita, no fundo, na soberania do indivíduo sobre a sua própria existência) implicasse necessariamente uma nova decisão sobre o limiar além do qual a vida cessa de ser politicamente relevante, é então somente "vida-sacra", e como tal, pode ser impunemente eliminada. Toda sociedade fixa esse limite, toda sociedade - mesmo a mais moderna - decide quais sejam os seus "homenzinhos sacros". É possível, aliás, que este limite, do qual depende a politização e a exceptio da vida natural na ordem jurídica estatal não tenha feito mais do que alargar-se na história do Ocidente e passa hoje - no novo horizonte biopolítico dos estados de soberania nacional - necessariamente ao interior de toda vida humana e de todo cidadão. A vida nua não está mais confinada a um lugar particular ou em uma categoria definida, mas habita o corpo biológico de cada ser vivente" (AGAMBEN, 2004, p. 135).
} 
Sob tais perspectivas, faz-se indispensável refletir sobre o epicentro do estado de exceção, esse que se constitui por um sistema de ideias, influências e técnicas de poder que se refletem diretamente no âmbito jurídico, e que violentam o meio ambiente, a vida em sua multiplicidade de formas, e essencialmente, a vida humana - expressa na vida dos refugiados, dos mendigos, dos consumidores falhos, dos despossuídos de crédito. Tais refugos humanos se apresentam desde o nascimento em débito com o poder soberano, esse que decide acerca da vida e da morte, num habitat cada vez mais inóspito e insalubre.

\subsection{Aspectos socioambientais}

De acordo com as temáticas debatidas até o presente momento, é possível considerar que o meio habitado pelo ser humano está completa e integralmente mergulhado num campo político-econômico em que as relações e decisões emanadas pelo poder supremo se sobressaem e alcançam direta e completamente o ser humano e o meio ambiente.

Essa racionalidade jurídico-econômica que se sobrepõe à racionalidade política torna-se o agente motivador dos conflitos humanos e ambientais vivenciados pela sociedade atual, especialmente no que tange à manutenção da obediência às regras impostas aos cidadãos pelo estado de exceção permanente em curso.

Sob a prática ideológica da superposição dos fatores econômicos em face aos socioambientais validados pelo Estado, surge, inevitavelmente, a exploração intensiva e sistemática dos bens naturais, os imperativos da sociedade da opulência, do ciclo ininterrupto da produção e do consumo. É como se todos os atos e procedimentos realizados por uma parcela dos indivíduos fossem minimamente calculados por núcleos autônomos do poder econômico, dotados de determinado saber, que exercem premeditadas ações de manipulação em prol da manutenção e potencialização do modelo produtivista e consumista atual.

Numa análise contemporânea acerca dos problemas que envolvem o meio ambiente, especialmente sobre as influências sofridas pela sociedade humana diante do meio de plena produção e consumo, é possível compreender tal fenômeno histórico com base nas causalidades das premissas mercadológicas refletido na ordem social, jurídica e ambiental moderna, nos diferentes âmbitos da sociedade, inclusive nos bens naturais. Os impactos, ou seja, os custos decorrentes dessa dinâmica, são inúmeros, dentre eles:

a) Holocausto: a agressão natural e humana da vida levada ao inimaginável, no qual "os campos de concentração escancararam a definição de homem, mostrando em toda a sua nudez que aquilo que a contemporaneidade considera humano é uma definição frágil e efêmera, sem maiores dificuldades, pode ser suspensa pelo poder soberano" (BAZZANELLA, 2018, p. 51). O poder soberano, por intermédio de tal prática, desumaniza, tira a identificação e reduz o homem à condição de animal desprovido de locução, sentido e pensamento no momento em que o comprime à irracionalidade. "Quando vida e política, divididos na origem e articulados entre si através da terra de ninguém do estado de exceção, na qual habita a vida nua, tendem a identificar-se, então toda a vida torna-se sacra e toda a política torna-se exceção" (AGAMBEN, 2010, p. 144). Nesse âmbito, o corpo é desligado do seu estado psíquico e político e abandonado às atrocidades, à fome, ao frio, à morte.

Em tal estado biológico de mera vida nua, se desenvolvem "o fascismo e o nazismo, dois movimentos biopolíticos em sentido próprio que fazem da vida natural o local por excelência da decisão soberana" (AGAMBEN, 2010, p. 125). Nessa situação, a vida - exposta a uma violência sem 
precedentes - se confunde com a política. É a inclusão da vida nua, meramente biológica, sob a faculdade e à disposição do Estado.

b) A exclusão dos desiguais na sociedade contemporânea: como resultado da hegemonia política combinada com a voracidade dos privilégios econômicos - associado à inclusão dos bens naturais e das condições de absoluta afirmação e legalização do sistema de produção e consumo -, tem-se como consequência a priorização do desenvolvimento exclusivamente econômico: a miséria, o desemprego em massa, a precária assistência à saúde, o descaso com uma educação de qualidade em todos os níveis, as doenças psicossociais que atualmente atingem elevada parcela da população, a ausência de vida qualitativa ante a escassez dos bens. População essa que sobrevive enfrentando os diuturnos desgostos e dificuldades para manter-se viva num ambiente inóspito, agressivo, em que as adversidades sociais e ambientais contemporâneas representam ameaças constantes a serem enfrentadas em face à subsistência da vida em sua totalidade e, entre essas, à vida humana.

A segregação dos desiguais da sociedade humana é exaltada pelo inegável totalitarismo político mundial acompanhado da competitividade e da globalização econômica, essa que é seguida de uma estratificação social e cultural que rechaça os dessemelhantes de maneira desprezível, egoísta, não refletida, ausente de qualquer solidariedade, compaixão ou pensamento coletivo. É a explícita demonstração de que "a sociedade hoje é regressiva. Ela é cega à sua própria história, que se organiza sem ela e a elimina" (FORRESTER, 1997, p. 77). Uma sociedade carente de memória cultural e conhecimento científico para compreender que na sua genealogia há resquício de uma codificação genética afrodescendente, indígena, judia, ignorada e repulsada nesse momento pela sociedade de plena produção e pleno consumo.

c) Crimes ambientais: o Brasil é um país que mantém a necessidade eminente de diminuição dos passivos ambientais e a manutenção dos bens naturais que ainda remanescem; possui uma vasta legislação ambiental, mas inexequível que, diante da violência e do abandono perpetrado e vivenciado pela instauração do estado de exceção permanente, oscila frequentemente frente às urgências do modelo desenvolvimentista em curso. Além disso, o país cultua insustentáveis perspectivas no que tange à racionalização da vida mediante a conservação de discursos e valores econômicos, como o trabalho, a renda ou a lucratividade em absoluto prejuízo ao desenvolvimento da assistência à saúde, à educação com qualidade, às dignas condições de vida e moradia da população, dentre outros.

d) Astigmatismo do ordenamento jurídico brasileiro: depois de aproximadamente 13 (treze) anos de debate no Congresso Nacional Brasileiro, no ano de 2012 foi publicada uma nova legislação intitulada Lei de Proteção da Vegetação Nativa (LPVN) (Lei no 12.651, de 25 de maio de 2012, alterada pela Lei 12.727 , de 17 de outubro de 2012), comumente conhecida como Novo Código Florestal, a qual traz regulamentações sobre a exploração, conservação e recuperação da vegetação nativa em todo o território nacional. É um conjunto de dispositivos que concede proteção legal ao ecossistema terrestre nativo, tais como florestas, campos, caatingas e cerrados.

Dentre as inúmeras alterações realizadas na LPVN, decorreram algumas modificações polêmicas que atenuaram a proteção dos espaços ou dos bens que se encontravam protegidos originalmente pela Lei n. 4.771/65, sendo que alguns aspectos, anteriormente disciplinados, perderam sua função ecológica.

e) Mercantilização da natureza: num evidente incentivo público de ratificar discursivamente que é importante e benéfico aquilo que é rentável, foram implementadas pela estrutura governamental iniciativas que consistem basicamente em ofertar algum benefício financeiro àqueles que se 
propõem a preservar o meio ambiente. Por exemplo, o Pagamento por Serviços Ambientais (PSA), ou ainda, foram implementadas medidas que explicitam o caráter mercadológico atribuído aos bens naturais, como a compensação de reserva legal, receita proveniente dos créditos da venda de carbono, valores atribuídos à desapropriação para destinação de unidade de conservação.

Algumas consequências coletivas vivenciadas na polis, oriundas da supremacia do capital e do poder econômico em face às diretrizes políticas e socioambientais, podem ser vislumbradas diariamente. Essa estrutura deflagra não só a escassez da água, a erosão do solo e a destruição da biodiversidade local, mas, também, resulta inevitavelmente na ausência de políticas públicas de qualidade na educação, na saúde, na precarização das relações de trabalho, renda e dignidade humana. Além disso, situações como essas promovem o individualismo, bem como, comprovam a forma como se estabelecem as relações e os mecanismos de poder com fulcro no custo-benefício da atividade econômica.

Isso porque "a íntima correlação entre crescimento econômico e maior felicidade é amplamente considerada uma das verdades menos questionáveis, talvez até a mais auto evidente" (BAUMAN, 2009 , p. 08) pela sociedade. E, sob essa suposta veracidade, o trabalho, a produtividade, a competitividade, o consumo e o uso ilimitado dos bens naturais se tornam procedimentos imprescindíveis à manutenção de uma equivocada vida segura, plena, eternizada no efêmero instante do consumo.

\section{CONSIDERAÇÕES FINAIS}

Mediante o exposto neste artigo, constata-se que se faz indispensável uma mudança de paradigma, para que se possa cogitar um entendimento socioambiental progressivo junto à elaboração de um novo ethos e de novas práticas políticas, sociais, ambientais e econômicas, contrariando a densa corrente de conformismo que acomete as sociedades humanas - inclusive as mais intelectualizadas - na contemporaneidade.

O entendimento exposto, fundamentado no pensamento agambeniano, ratifica a necessidade de uma política que faça as contas com a cisão da biopolítica fundamental do Ocidente para pôr fim à guerra civil que divide os povos e as cidades na terra (AGAMBEN, 2010). Ou seja, somente a partir do momento em que os seres humanos deixarem de ser entendidos, pelo Estado, como dígitos que compõem um numeral, é que se poderá compreender a vida humana fora do contexto meramente biológico - no qual os cidadãos varões pagam a sua participação na vida política com uma incondicional sujeição a um poder de morte e a vida, essa que entra na cidade somente na dupla exceção da matabilidade e da insacrabilidade (AGAMBEN, 2010).

Nessas circunstâncias, corresponde aos súditos a faculdade de não desobedecer, mas de resistir à violência exercitada sobre sua própria pessoa (AGAMBEN, 2010). Ou seja, de refletir, forçar o pensamento e a compreensão da realidade massificada, de servidão voluntária, de submissão a este sistema econômico-político-jurídico contemporâneo. Importante ressaltar que o corpo biológico dos indivíduos produtores e consumidores elegeu, convalidou e permanece continuamente sob o domínio de tais premissas violentas, sendo que em contrapartida abre mão de parcela significativa da liberdade de ser e agir. Igualmente, abre mão da possibilidade de viver num ambiente sadio e desenvolver suas potencialidades humanas vitais.

Em outras palavras, o que se pode ver no horizonte atualmente são as ameaças ainda mais tangíveis que afetam a sobrevivência neste Planeta, devido a um desenvolvimento fomentado exclusivamente por interesses econômicos atemorizantes, que colocam diuturnamente todas as 
formas de vida num perigo iminente. Perigo de não sobrevier num ambiente depredado, ríspido e hostil, em permanente risco de reprodução sem as mínimas qualidades biológicas que promovam o bem-estar socioambiental.

Assim, é indispensável que haja uma reflexão profunda e contínua voltada à condição limite vivenciada na sociedade dos indivíduos, a qual pode ser enfrentada mediante uma mudança na cosmovisão que seja capaz de atribuir um novo sentido à existência de cada ser humano, bem como da diversidade de sociedades humanas e também dos ecossistemas. Isto porque não parece que a solução seja simples, única e pontual, como por exemplo alterar o regime, as leis, as prioridades ambientais, se não for possível modificar o axioma acerca do modo de vida humano contemporâneo.

Em posse dessa nova ordem de pensamentos, o indivíduo deixa de ser um item supérfluo, um resíduo subordinado à máquina governamental e ao capital e passa a tomar uma dimensão prioritária, no sentido de valoração íntima de cada pessoa, dos bens naturais, do espaço compartilhado pela sociedade, dos problemas coletivos, o que pode reduzir as fraturas sociais e impondo uma nova ética. $E$, ainda, assentar bases sólidas e fidedignas em outras perspectivas de sociedade, de economia, de direito, que necessariamente incidirão sobre o conceito e sobre as práticas de desenvolvimento regional. Tais reavaliações poderão permitir a implantação de formas diferenciais de desenvolvimento integral que considerem os fatores econômicos, ambientais, sociais e políticos, que conduzem à realização de uma vida coletiva solidária, que valorizem o homem, os bens públicos e difusos, e especialmente a natureza.

Sob tal reflexão, o homem e o meio em que habita necessitam redescobrir e integralizar-se numa posição fundamental, digna no discurso político, momento em que os benefícios e os efeitos colaterais decorrentes do progresso serão compensados e divididos equitativamente. Em outros termos, o fomento ao progresso econômico tem sobrecarregado os sistemas ecológicos e sociais, especialmente no que tange à divisão das populações humanas quando sob os ricos recaem os benefícios das mudanças, e aos pobres, em sua maioria, incidem os malefícios, os custos advindos do desenvolvimento exclusivamente econômico. Adotar padrões de produção, consumo e reprodução que protejam os direitos humanos fundamentais dos desiguais e as capacidades regenerativas da Terra faz parte deste reposicionamento do conceito e das práticas inerentes ao desenvolvimento regional.

Por obviedade, faz-se imprescindível reconhecer o alcance restrito dos esforços que resultaram nas linhas que compõe este artigo, cujo limite pode ser objeto de futuras pesquisas dos próprios autores, bem como de leitores motivados por tais perspectivas.

\section{REFERÊNCIAS}

ABBAGNANO, Nicola. Dicionário de Filosofia, tradução da 1a edição brasileira coordenada e revisada por Alfredo Bossi, revisão da tradução e tradução de novos textos Ivone Castilho Benedetti. 5. Ed. São Paulo: Martins Fontes, 2007.

AGAMBEN, Giorgio. O Poder Soberano e a Vida Nua I, tradução de Henrique Burigo. 2. ed. Belo Horizonte. Editora UFMG: 2010.

AGAMBEN, Giorgio. Estado de Exceção, tradução de Iraci D. Poleti. 2. ed. São Paulo: Boitempo, 2004. 
AGAMBEN, Giorgio. O Reino e a Glória: uma genealogia teológica da economia e do governo: Homo Sacer II. Tradução de Selvino J. Assmann. São Paulo: Boitempo, 2011.

ARENDT, Hannah. A condição humana. Tradução Roberto Raposo, revisão técnica: Adriano Correia. 11. ed. Rio de Janeiro. Forense Universitária, 2014.

BAUMAN, Zygmunt. Vidas Desperdiçadas. Tradução Carlos Alberto Medeiros. Rio de Janeiro: Jorge Zahar Ed., 2009.

BAUMAN, Zygmunt. Modernidade e Ambivalência. Rio de Janeiro: Jorge Zahar, 1999.

BAZZANELLA, Sandro Luiz. A CENTRALIDADE DA VIDA EM NIETZSCHE e AGAMBEN fRENTE À METAFíSICA OCIDENTAL E A BIOPOLÍTICA CONTEMPORANEA. Florianópolis: UFSC, 2010, P. 94. Tese de doutorado disponível em: https://repositorio.ufsc.br/handle/123456789/94701\#: :text=em\%20Ci\%C3\%AAncias\%20Humana s-

,A\%20Centralidade\%20da\%20vida\%20em\%20Nietzsche\%20e\%20Agamben\%20frente,ocidental\%2 0e\%20a\%20biopol\%C3\%ADtica\%20contempor\%C3\%A2nea\&text=Nietzsche\%20ao\%20conceber\%2 0a\%20vida,mediocrizante\%20presente\%20em\%20seu\%20tempo. Acessado em 01/08/2020.

BAZZANELLA, Sandro Luiz. Agamben e os Pressupostos do Dispositivo Governamental e Oikonomico. Revista Profanações, ano 2, n. 2, p. 37-61, jul/dez. 2015.

BAZZANELLA, Sandro Luiz (Org). Crônicas do Desenvolvimento II. Editora Nova Letra. Canoinhas, 2013.

BAZZANELLA, Sandro Luiz (Org). A atualidade de Aushwitz - reflexões acerca da obra "O que resta de Auchwitz: o arquivo e a testemunha. São Paulo. LiberArs, 2018.

BOTTOMORE, Tom. Dicionário do pensamento marxista. Rio de Janeiro: Jorge Zahar Ed., 2001.

COMISSÃO MUNDIAL SOBRE MEIO AMBIENTE E DESENVOLVIMENTO (CMMAD). Nosso futuro comum. Rio de Janeiro: Fundação Getúlio Vargas, 1987.

FOUCAULT, Michel. Nascimento da Biopolítica. Tradução de Eduardo Brandão. São Paulo. Martins Fontes, 2008 (coleção tópicos).

FORRESTER. Viviane. O Horror Econômico. Tradução de Álvaro Lorencini. São Paulo: Editora da Universidade Estadual Paulista, 1997.

MARCHESAN, Jairo. A água no contexto da suinocultura na sub-bacia do Lajeado dos Fragosos Concórdia (SC). 2017. 288 f. Tese (Pós-graduação em Geografia). Universidade Federal de Santa Catarina, Florianópolis, 2007.

WEBER, Max. A Ética Protestante e o Espírito do Capitalismo. 1. ed. São Paulo: Pioneira, 1905. 